\title{
Effect of Chronic Angiotensin-Converting Enzyme Blockade on Pressor Responses to Exogenous Angiotensin II, Noradrenaline and Vasopressin in Deoxycorticosterone Acetate Salt (DOCA)-Induced Hypertensive Rats
}

\author{
Ee-Kiang GAN, Alias ABAS and Aishah LATIFF \\ School of Pharmaceutical Sciences, Universiti Sains Malaysia, Minden. Penang, Malaysia \\ Accepted June 18, 1984
}

\begin{abstract}
Effect of chronic angiotensin converting enzyme blockade on the pressor response to exogenous angiotensin $\mathrm{II}$, noradrenaline and vasopressin were evaluated in DOCA-salt induced hypertensive rats using teprotide. The blood pressure of rats receiving teprotide chronically was reduced markedly. The pressor responses to exogenous angiotensin II was accentuated, while that of noradrenaline and vasopressin were significantly reduced. It is concluded that besides the angiotensin converting enzyme blocking action, the decrease in sensitivity of the pressor response to noradrenaline and vasopressin may contribute towards the antihypertensive activity of teprotide given chronically.
\end{abstract}

Angiotensin-converting-enzyme inhibitor (ACEI) is a powerful antihypertensive agent whose mechanism(s) of action is poorly understood. Initially, its antihypertensive property was thought to be mediated via the reduction in vasoactive angiotensin II concentration through the blockade of conversion of angiotensin I to angiotensin II (1). Blockade of conversion of angiotensin I to angiotensin II cannot account for its angihypertensive efficacy because ACEI is effective even in cases of hypertension whose plasma renin level is low (2). Others had reported that ACEl potentiates the vasodepressor response to bradykinin (3). Yet another possibility of its antihypertensive efficacy may be the result of its effect on the pressor responsiveness to angiotensin 11 , noradrenaline and vasopressin. since these three are principle pressor agents found naturally in the body that had been implicated in the regulation of normal blood pressure (b.p.) and in the pathogenesis of hypertension (4-6). It is therefore useful to study chronic teprotide ( Glu-Trp-Pro-Arg-Pro-Gin-Ile-Pro-Pro) administration on pressor responses to exogenous angiotensin 11 , noradrenaline and vasopressin in deoxycorticosterone acetate
(DOCA)-salt induced hypertensive rats. This hypertensive model was chosen because it has been demonstrated that the plasma renin activity is Iow in DOCA-salt hypertensive rats (7).

\section{Materials and Methods}

Male Albino rats weighing 200-300 g were used in the present investigation. All rats underwent unilateral left nephrectomy under ether anaesthesia through an incision made on the dorsal region and subsequently closed in two layers, muscle layer with sutures and skin with surgical clips. All rats were kept at room temperature and allowed one week to recover. No attempts were made to control the humidity of the room.

The DOCA-salt regimen was initiated on the 8th day after unilateral nephrectomy. This consisted of injections of DOCA (Sigma Chemical Co.). $15 \mathrm{mg} / \mathrm{kg}$, subcutaneously on alternate days for a period of 8 weeks. During this time, rats drank $1 \% \mathrm{NaCl}$ ad libitum and were allowed free access to commercial food pellets. Weekly systolic blood pressure was measured by tail plethysmography, connected to a physiograph in prewarmed $\left(40^{\circ} \mathrm{C}\right.$ for $15 \mathrm{~min}$ ) rats as reported by Krakoff et al. (8). 
Only rats with a conscious systolic blood pressure greater than $150 \mathrm{mmHg}$ were considered as hypertensive and used in the present investigation. Teprotide injections, $200 \mathrm{ng} / \mathrm{kg}$, given intraperitoneally, twice daily at $12 \mathrm{hr}$ intervals were given to each rat for a period of 4 weeks in the experimental group, while in the control group, each rat received similar volumes of saline injection for the same period of time. During this period, conscious systolic blood pressure was measured weekly as before for all rats.

For purposes of recording the pressor responses, each rat was anaesthetised with sodium pentobarbital (Nembutal, Abbott), $40 \mathrm{mg} / \mathrm{kg}$, injected intraperitoneally. Following anaesthesia, the trachea was cannulated with polyethylene tubing (PE 205). Two other catheters (PE 10): one was placed in the left jugular vein for intravenous injection, while the other was placed in the left carotid artery for monitoring of blood pressure. Both catheters had been previously filled with $0.9 \%$ $\mathrm{NaCl}$ containing $50 \mathrm{U} / \mathrm{ml}$ heparin. The arterial catheter was connected to statham pressure transducer coupled to the polygraph (Grass Model) on which direct blood pressure recordings were made. Ganglion blockade was induced in all rats by administration of pentolinium tartrate (May \& Baker), $2.5 \mathrm{mg} /$ rat $(0.5 \mathrm{mg}$ given intravenously and $2.0 \mathrm{mg}$ given subcutaneously), to give a more stable blood pressure (9). Following stabilization of blood pressure in each rat, the dose-response relationships to three submaximal doses of angiotensin II (Hypertensin, Ciba)* noradrenaline and vasopressin (both from Sigma Chemical Co.), respectively, were determined. The doses of angiotensin II and noradrenaline used were similar, i.e., 10, 20 and $40 \mathrm{ng} / \mathrm{rat}$ (equivalent to 40,80 and $160 \mathrm{ng} / \mathrm{kg}$ ), respectively, while the doses for vasopressin were 2.5, 5 and 10 I.U./rat (equivalent to 10 . 20 and $40 \quad 1 .(\mathrm{U} . / \mathrm{kg}$ ). Between subsequent injections, the blood pressure was allowed to return to baseline level and this usually took 3-5 $\mathrm{min}$.

Statistics: In comparing the effect of teprotide on the conscious blood pressure in the various groups, Student's t-test was used to determine significance between groups before and during treatment in both treated and control animals. However, the slopes and the various points obtained from the doseresponse relationship were compared bebetween the control and treated groups by analysis of variance ( $F$-test) according to the method described by Duncan and coworkers (10).

\section{Results}

Chronic daily administration of ACEI teprotide for four weeks markedly reduced the conscious systolic blood pressure of DOCA-salt-induced hypertensive rats, as shown in Table 1. This reduction was observed one week after the commencement of teprotide treatment, and as much as 30\% reduction was recorded four weeks later.

The dose-response relationship to submaximal doses of angiotensin II is depicted in Fig. 1. It can be seen that chronic administration of teprotide accentuated the pressor responses of angiotensin $I I$. In contrast, chronic administration of teprotide blunted the pressor responses to noradrenaline (Fig. 2) and vasopressin (Fig. 3) as shown by the right shift of the dose-response curve. The results were statistically significant.

Table 1. Conscious blood pressure of DOCA-salt-induced hypertensive rats before and during teprotide treatment

\begin{tabular}{ccccccc}
\hline & & \multicolumn{3}{c}{$\begin{array}{c}\text { Before } \\
\text { treatment }\end{array}$} & 7 & \multicolumn{2}{c}{ Days after treatment } \\
& & & & 14 & 21 & 28 \\
Control & 7 & $171 \pm 3$ & $179 \pm 6$ & $167 \pm 6$ & $197 \pm 8$ & $200 \pm 8$ \\
Treated & 7 & $173 \pm 3$ & $161 \pm 3^{*}$ & $148 \pm 4^{*}$ & $134 \pm 3^{* *}$ & $126 \pm 3^{* *}$ \\
\hline
\end{tabular}

Results are expressed in $\mathrm{mmHg} \pm$ S.E.M. ${ }^{*} \mathrm{P}<0.05,{ }^{*} \mathrm{P}<0.01$

* Generously donated by Ciba-Geigy, Basle. Switzerland. 


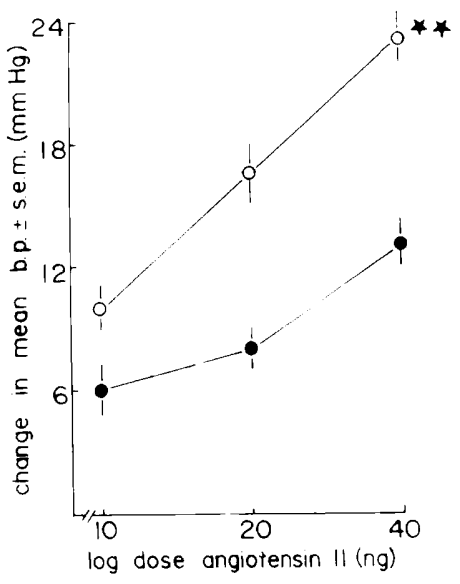

Fig. 1. Dose-response curve to angiotensin 11 in ACEl treated (O) and in control (O) DOCA-salt hypertensive rats. Each point is the mean \pm S.E.M. of 7 experiments. $\star \star P<0.01$.

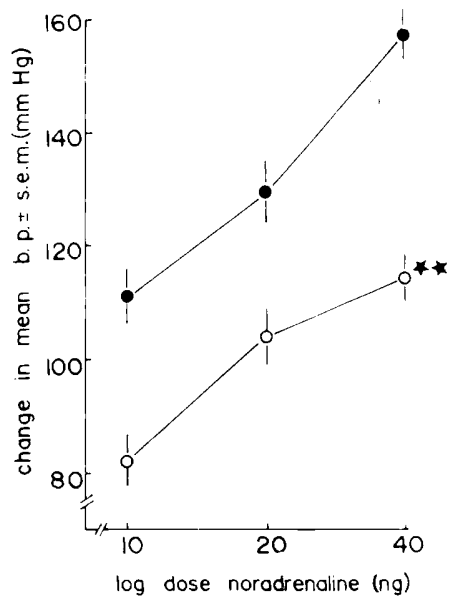

Fig. 2. Dose-response curve to noradrenaline in ACEl treated (O) and in control (O) DOCA-sa!t hypertensive rats. Each point is the mean \pm S.E.M. of 7 experiments.

$\star \star P<0.01$

\section{Discussion}

The blood pressure of DOCA-salt hypertensive rats was greatly reduced following chronic administration of ACEl teprotide. confirming the efficacious effect of teprotide

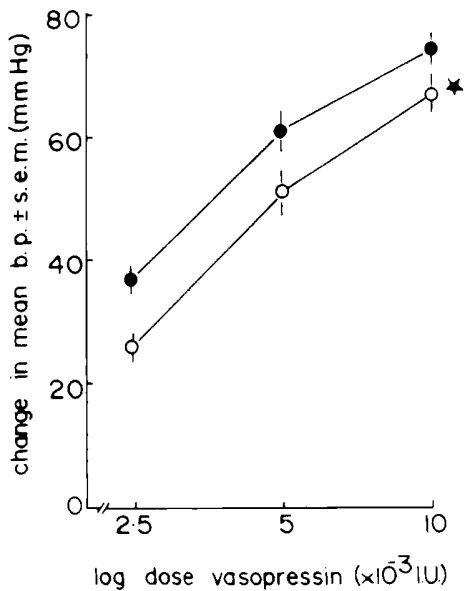

Fig. 3. Dose-response curve to vasopressin in ACEl treated (O) and in control (O) DOCA-salt hypertensive rats. Each point is the mean \pm S.E.M. of 7 experiments. $\star P<0.05$.

as an antihypertensive agent. This is in agreement with earlier reports (11-13). Although plasma angiotensin II level was not determined in the present study, chronic administration of teprotide is expected to reduce further the already existing low levels of circulating angiotensin II in the plasma of DOCA-salt induced hypertensive rats. Thus it is not surprising to note that the vasopressor effect to exogenous angiotensin 11 is accentuated in treated animals. This observation had also been reported for normotensive rats and the increase in sensitivity of the pressor response to exogenous angiotensin 11 had been attributed to the decrease in circulating angiotensin $\mid 1$ which may result in greater availability of vascular receptor sites to the introduced exogenous angiotensin II $(14,15)$. It is possible that a similar mechanism is operative here.

A close relationship is known to exist between renin-angiotensin and the sympathetic nervous system in blood pressure regulation. There is an abundance of evidence to suggest that angiotensin II exerts part of its pressor effect via the sympathetic nervous system and that the sympathetic nervous system (through noradrenaline) may exert its effect through angiotensin II in controlling 
the blood pressure $(16,17)$. In relation to this, angiotensin 11 has been shown to enhance the vasoconstrictor effect of noradrenaline (18), and the vasopressor effect of sympathetic nervous stimulation increases greatly by infusion of angiotensin II (19). The fact that a blockade of angiotensin II formation through chronic converting enzyme inhibition reduces the sensitivity of the pressor response to noradrenaline further supports the close synergistic relationship that exists between the two systems. Of particular importance is the synergistic relationship between these two systems that was shown to exist in DOCA-salt hypertensive rats in which the renin-angiotensin system is known to be depressed. It infers that slight changes in the concentration of angiotensin II is all that is necessary for diminishing the vasopressor effect of noradrenaline.

Vasopressin had been reported to play an important role in some forms of experimental hypertension $(6,20,21)$ and that a close relationship also existed between vasopressin and the renin-angiotensin system $(22,23)$. It had also been shown (24) that when circulating angiotensin 11 levels are reduced in normal rats, the pressor response to vasopressin is increased. Morton et al. (25) reported that DOCA-salt hypertensive rats have a higher plasma vasopressin concentration and suggested that this increase in vasopressin concentration may contribute to the suppression of the renin-angiotensin system. In the rat, teprotide had also been known to enhance release of plasma vasopressin (26). It is therefore reasonable to assume that in the present study, the DOCAsalt hypertensive rats receiving teprotide had a substantial increase of circulating vasopressin. As the results indicated, such an increase may blunt the vasopressor effect of the injected exogenous vasopressin. It may be possible that prolonged elevation of vasopressin concentration in DOCA-salt hypertension reduces the availability of the vascular receptor site to exogenous vasopressin, a site where vasopressin is known to act in eliciting the vasopressor response.

It is therefore highly probable that blunting of the pressor response to noradrenaline and vasopressin by teprotide, besides the in- hibition of converting enzyme, contributes towards its antihypertensive effect. This may help explain the efficacious effect of teprotide as an antihypertensive agent, particularly in cases where the renin level is low as in the present case.

\section{References}

1 Engel, S.L., Schaeffer, T.R., Gold, B.I. and Rubin, B.: Inhibition of pressor effects of angiotensin I and augmentation of depressor effects of bradykinin by synthetic peptides. Proc. Soc. Exp. Biol. Med. 140, 240-244 (1972)

2 Vollmer, R.R., Boccagno, J.A., Harris, D.N. and Murthy, V.S.: Hypotension induced by inhibition of angiotensin-converting enzyme in pentobarbital-anesthetized dogs. Eur. J. Pharmacol. $51,39-45(1978)$

3 Ferreira, S.H.: A bradykinin-potentiating factor (BPF) present in the venom of Bothrops jararaca. Br. J. Pharmacol. 24, 163-169 (1965)

4 Louis, W.J., Doyle, A.E. and Anavekar, S.: Plasma norepinephrine leveis in essential irypertension. N. Engl. J. Med. 288, 599-601 (1973)

5 Brunner, H.R., Garvas, H. and Laragh, J.H.: Specific inhibition of the renin-angiotensin system: A key to understanding blood pressure regulation. Prog. Cardiovasc. Dis. 17, $87-98$ (1974)

6 Mohring, J., Mohring, B., Petri, M. and Haack: D.: Is vasopressin involved in the pathogenesis of malignant deoxycorticosterone hypertension in rats? Lancet 1, 170-173 (1976)

7 Suzuki, H., Kondo, K., Handa, M. and Saruta, T.: Role of the brain iso-renin-angiotensin syste.n in experimental hypertension in rats. Clin. Sci. $61,175-180$ (1981)

8 Krakoff, L.R., Selvadural, R. and Sutter, E.: Effect of methyl-prednisolone upon arteria! pressure and the renin-angiotensin syste $n$ in tho rat. Am. J. Physiol. 228, 613-617 (1975)

9 Peart, W.S: A new method of large scale pieparation of hypertension, with a note on its assay. Biochem. J. 59, 300-302 (1955)

10 Duncan, R.C., Knapp, R.G. and Miller, M.C.: Tests of hypotheses on population means. In Introductory Biostatistics for the Health Sciences. Edited by Duncan, R.C., Knapp. R.G. and Miller. M.C., p. 79-96. Wiley Medical John Wiley \& Sons, New York (1977)

11 Bing. J. and Poulsen, K.: Time course of change in plasma renin after blockade of the renin system: Studies of conscious and anestheized. normal adrenaleciomized and spontaneously hypertensive rats. Acta Pathol. Microbiol. Scand. 
83, 454 (1975)

12 Bengis, R.G., Coleman, T.G., Young, D.B. and McCaa, R.E.: Long term blockade of angiotensin formation in various normotensive and hypertensive rat models using converting enzyme inhibitor (SO 14, 225). Circ. Res. Supp. I, 45-53 (1978)

13 Hutchinson, J.S., Mendelsohn, F.A.O. and Doyle, A.E.: Blood pressure responses of conscious normotensive and spontaneously hypertensive rats to the intracerebroventricular and peripheral administration of angiotensin converting enzyme inhibitor, captopri!. Hypertension 2, 546-550 (1980)

14 Thurston. H. and Laragh, J.H.: Prior receptor occupancy as a determinant of the pressor activity of infused All in the rat. Circ. Res. 36. 113-117 (1975)

15 Jaegar, P., Fergusan, R.K., Brunner, H.R., Kirchertz, E.J. and Gavras, H.: Mechanism of blood pressure reduction by teprotide (SO 20.881) in rats. Kidney Int. 13, 289-296 (1978)

$16 \mathrm{Ng}$, K.K.F., Duffy, S., Louis, W.J. and Doyle, A.E.: Interaction of angiotensin II with catecholamines in the circulation of the dog and cat Clin. Sci. Mol. Med. 51, 451S-454S (1976)

17 Ichikawa, S., Johnson, J.A., Fowler, W.L. Payne, C.G., Kurz, K. and Keitzer, W.F.: Pressor responses to noradrenaline in rabbits with 3 -day and 30 -day renal artery stenosis. The role of angiotensin 11. Circ. Res. 43, 437-446 (1978)

18 Khairallah, P.A., Davila, D., Papanicolaou, N., Glende, N.M. and Meyer, P.: Effects of angiotensin infusion on catecholamine uptake and reactivity in blood vessels. Circ. Res. 28/29, Supp. II, 96-106 (1971)

19 Panisset, J.C. and Bourdois, P.: Effect of angiotensin on the response to noradrenaline and sympathetic serve stimulation and on ${ }^{3} \mathrm{H}$ noradrenaline uptake in cat mesenteric blood vessels. Can. J. Physiol. Prarmacol. 46, 125-131 (1968)

20 Padfield, P.L., Lever, A.F.. Brown, J.J., Morton, J.J. and Robertson, J.I.S.: Changes of vasopressin in hypertension: cause or effect? Lancet 1, 1255-1257 (1976)

21 Crofton, J.T., Share, L., Shade, R.E., Leckwon, W.J., Manning, M. and Sawyer, W.H.: The importance of vasopressin in the development and maintenance of DOCA-salt hypertension in the rat. Hypertension 1, 31-38 (1979)

22 Vander, A.J.: Inhibition of renin release in the dog by vasopressin and vasotocin. Circ. Res. 23, 605-609 (1968)

23 Malvin, R.L.: Possible role of the reninangiotensin system in the regulation of antidiuretic hormone secretion. Fed. Proc. 30, 1383-1386 (1971)

24 Spertini, F., Brunner, H.R., Waeber, B. and Gavas, $H_{\text {.: }}$ The opposing effects of chronic angiotensin-converting enzyme blockade by captopril on the responses to exogenous angiotensin 11 and vasopressin VS noradrenaline in rats. Circ. Res. 48, 612-618 (1981)

25 Morton, J.J., Garcia Del Rio, C. and Hughes, M.J.: Effect of acute vasopressin infusion on blood pressure and plasma angiotensin 11 in normotensive and DOCA-salt hypertensive rats Clin. Sci. 62, 143-149 (1982)

26 Knepel, W. and Meyer, D.K.: Infiuence of converting enzyme inhibition on the release of vasopressin induced by angiotensin. $\mathrm{Br}$. J. Pharmacol. 71, 337-341 (1980) 